University of Nebraska - Lincoln

DigitalCommons@University of Nebraska - Lincoln

Faculty Publications from the Harold W. Manter Laboratory of Parasitology

2005

SYSTEMATICS OF MESOCESTOIDES (CESTODA:

MESOCESTOIDIDAE): EVALUATION OF MOLECULAR AND

MORPHOLOGICAL VARIATION AMONG ISOLATES

\author{
Kerry A. Padgett \\ California Department of Health Services, kpadgett@dhs.ca.gov \\ Steven A. Nadler \\ University of California - Davis, sanadler@ucdavis.edu \\ Linda Munson \\ University of California - Davis \\ Ben Sacks \\ University of California - Davis \\ Walter M. Boyce \\ University of California - Davis, wmboyce@ucdavis.edu
}

Follow this and additional works at: https://digitalcommons.unl.edu/parasitologyfacpubs

Part of the Parasitology Commons

Padgett, Kerry A.; Nadler, Steven A.; Munson, Linda; Sacks, Ben; and Boyce, Walter M., "SYSTEMATICS OF MESOCESTOIDES (CESTODA: MESOCESTOIDIDAE): EVALUATION OF MOLECULAR AND MORPHOLOGICAL VARIATION AMONG ISOLATES" (2005). Faculty Publications from the Harold W. Manter Laboratory of Parasitology. 713.

https://digitalcommons.unl.edu/parasitologyfacpubs/713

This Article is brought to you for free and open access by the Parasitology, Harold W. Manter Laboratory of at DigitalCommons@University of Nebraska - Lincoln. It has been accepted for inclusion in Faculty Publications from the Harold W. Manter Laboratory of Parasitology by an authorized administrator of DigitalCommons@University of Nebraska - Lincoln. 


\title{
SYSTEMATICS OF MESOCESTOIDES (CESTODA: MESOCESTOIDIDAE): EVALUATION OF MOLECULAR AND MORPHOLOGICAL VARIATION AMONG ISOLATES
}

\author{
Kerry A. Padgett*, Steven A. Nadler†, Linda Munson, Ben Sacksł, and Walter M. Boyce \\ Department of Veterinary Pathology, Microbiology, and Immunology, University of California, One Shields Avenue, Davis, California 95616. \\ e-mail: kpadgett@dhs.ca.gov
}

\begin{abstract}
A hypothesis-based framework was used to test if 3 genetic strains of Mesocestoides (clades A, B, and C) are distinct evolutionary lineages, thereby supporting their delimitation as species. For comparative purposes, 3 established cestode species, Taenia pisiformis, Taenia serialis, and Taenia crassiceps were assessed using the same methods. Sequence data from mitochondrial rDNA (12S) and the second internal transcribed spacer of nuclear rDNA (ITS-2) revealed derived (autapomorphic) characters for lineages representing clade A $(\mathrm{n}=6$ autapomorphies), clade $\mathrm{B}(\mathrm{n}=4)$, and clade $\mathrm{C}(\mathrm{n}=9)$ as well as T. pisiformis $(\mathrm{n}=$ $15)$ and T. serialis $(\mathrm{n}=12)$. Furthermore, multivariate analysis of morphological data revealed significant differences among the 3 genetic strains of Mesocestoides and between T. pisiformis and T. serialis. The level of phenotypic variation within evolutionary lineages of Mesocestoides and Taenia spp. tapeworms was similar. Results from this study support recognizing Mesocestoides clades A, B, and C as separate species, and provide evidence that clade B and Mesocestoides vogae are conspecific.
\end{abstract}

Traditionally, parasite species have been described using the Linnaean or similarity species concept, which is based primarily upon differences in morphological characteristics or host identity (Mayr, 1963). Although this species concept and its methods have proven useful for delimiting species of many macroparasites, it has been unsuccessful for certain other common parasites, including Mesocestoides spp. tapeworms, because of difficulties presented by morphological plasticity or, conversely, cryptic species. Identification and species delimitation of $\mathrm{Me}$ socestoides spp. tapeworms is difficult because of conflicts among key morphological characters (Loos-Frank, 1987) and a high degree of host-induced nonspecific morphological variation (Rausch, 1994). For example, Voge (1955) examined 6 putative Mesocestoides species from North America and concluded that the high degree of morphological variability warranted a complete revision of the genus. Furthermore, adult $\mathrm{Me}$ socestoides spp. with similar genetic characteristics have been isolated from a wide host and geographic range (Crosbie, Nadler et al., 2000; Crosbie, Padgett et al., 2000; Padgett and Boyce, 2004), thus indicating that there is reduced specificity for final hosts in some species of this genus. Clearly, Mesocestoides is a particularly problematic genus, but more broadly, there is limited value in using only similarity measures for delimiting parasite species.

Because efforts to distinguish among Mesocestoides species using morphological similarities have often failed, other approaches are needed. In an attempt to reduce the systematic error in nematode species delimitation, Adams (1998) recommended an amalgamation of phylogenetic species concepts (e.g., Cracraft, 1983) and evolutionary species concepts (e.g., Wiley, 1978). Using this methodology, species are recognized based upon evidence of independent evolutionary lineages reflected in the form of autapomorphies, i.e., derived character states unique to individuals of a species. This phylogenetic ap-

Received 9 July 2004; revised 29 March 2005; accepted 29 March 2005.

* Present address: Vector-Borne Disease Section, California Department of Health Services, 850 Marina Bay Parkway, Richmond, California 94804.

$\dagger$ Department of Nematology, University of California, One Shields Avenue, Davis, California 95616.

$\ddagger$ Veterinary Genetics Laboratory, School of Veterinary Medicine, University of California, One Shields Avenue, Davis, California 95616. proach to delimiting species allows for hypothesis testing and potential refutation. For example, Nadler et al. (2000) used this theoretical framework to evaluate Uncinaria spp. hookworms from 2 sympatric host species (California sea lions, Zalophus californianus, and northern fur seals, Callorhinus ursinus, collected from San Miguel Island, Channel Island National Park). They found that hookworms from each host species had autapomorphies characteristic of separate evolutionary lineages, indicating that each pinniped species hosted distinct hookworm species.

Recent molecular phylogenetic studies of Mesocestoides spp. revealed at least 3 distinct monophyletic groups (clades A, B, and C) in western North America (Crosbie et al., 1998, Crosbie, Nadler et al., 2000, Crosbie, Padgett et al., 2000). Clade A included acephalic metacestodes and adult tapeworms from dogs and coyotes, respectively. Clade B was composed of tetrathyridia from a dog and a western fence lizard (Sceloporus occidentalis), and clade $\mathrm{C}$ was composed of adult tapeworms from dogs. Although these studies showed Mesocestoides spp. isolates belong to separate clades, evolutionary species delimitation would benefit from population-level sampling of individuals and analysis of multiple genetic loci.

Compared to Mesocestoides, the species-level systematics of taeniid tapeworms is better resolved. Based on morphological analysis of adult specimens, there are approximately $40 \mathrm{rec}-$ ognized species in the genus Taenia (Hoberg et al., 2000). Many recent studies have shown high levels of interspecific variation for molecular characters that are useful for distinguishing species of Taenia (Bowles and McManus, 1994; Gasser and Chilton, 1995; De Queiroz and Alkire, 1997; NickischRosenegk et al., 1999). Because of the comparatively advanced state of species-level taeniid systematics, Taenia species provide a good standard for comparative analysis with other problematic cestode species such as Mesocestoides.

The objectives of this study were (1) to determine whether Mesocestoides clades A, B, and C are distinct evolutionary lineages that should be delimited as separate species; (2) to determine whether established species of Taenia show evidence of lineage independence using the same genetic loci and methods; and (3) to assess the extent of morphological variation among and within each clade of Mesocestoides and each species of Taenia. 


\section{MATERIALS AND METHODS}

\section{Primary characterization of samples}

With the exception of specimens acquired from museum or personal collections (certain Mesocestoides spp., T. pisiformis, and T. serialis), all tapeworm specimens used in this study were identified in the following manner. Metacestode and adult tapeworm samples were identified to genus using morphological characters. Because many Mesocestoides spp. metacestodes from domestic dogs lack apical suckers ("acephalic metacestodes"), morphological identification of these specimens was not possible. Instead, all tapeworms were tested independently by a PCR-RFLP assay targeting the second internal transcribed spacer region (ITS-2) of nuclear rDNA (Crosbie et al., 1998) and grouped according to distinct restriction fragment patterns, i.e., clade A, clade B, clade C, T. crassiceps, T. pisiformis, and T. serialis.

\section{Source of tapeworm material}

Mesocestoides spp. metacestodes (acephalic and tetrathyridial morphotypes) were obtained from domestic carnivores diagnosed with peritoneal cestodiasis throughout California and other locations in western North America (Table I). Tetrathyridia also were obtained from wildcaught deer mice (Peromyscus maniculatus) at 2 California sites (Table I). All larvae were preserved in $70 \%$ ethanol or frozen in sterile saline solution before genetic analysis.

Intact clade A Mesocestoides spp. adult tapeworms were obtained by necropsy from wild-caught coyotes (Canis latrans) killed by county trappers in 4 northern California counties (Mendocino, Napa, Sutter and Yuba). In addition, proglottids were acquired from dogs experimentally or naturally infected with adult Mesocestoides spp. tapeworms (clades B and C). Intact adult tapeworms of Mesocestoides spp. (clades A and C) were also obtained from island fox (Urocyon littoralis) during necropsy of animals that died of natural causes at 4 California Channel Islands (San Nicolas, San Miguel, Santa Catalina, and San Clemente). These adult tapeworms were preserved in $70 \%$ ethanol for genetic analysis. The anterior and posterior ends were removed from adult Mesocestoides that were used for morphological analysis (Table II). A subset of these tapeworms was deposited in the U.S. National Parasite Collection (USNPC), Beltsville, Maryland (accession numbers: clade A 093311; clade B, 093312; clade C, 093313). For comparison, voucher specimens from the USNPC were obtained of Mesocestoides kirbyi Chandler, 1944 (36898, type specimen), Mesocestoides variabilis Mueller, 1927 (51171, cotype), Mesocestoides manteri Chandler, 1942 (44941, type specimen), and Mesocestoides bassarisci MacCallum, 1921 (45604 and 45933).

Metacestodes of $T$. pisiformis and $T$. serialis were obtained from rabbits. Adult T. pisiformis were obtained from coyotes in Mendocino, Yuba, and Sutter counties; adult T. serialis were obtained from coyotes in Mendocino and Napa counties. Adult T. serialis also were obtained from an experimentally infected dog and a wild-caught mountain lion. For morphometric analyses, voucher specimens of adult $T$. pisiformis and $T$. serialis were obtained from the USNPC ( $T$. pisiformis accession numbers: 77533, 77801, 78502, 78503, 78511, 78734, 82562, and 78511; T. serialis accession numbers: 15794, 18104). Measurements were made for a total of $32 \mathrm{~T}$. pisiformis and $31 \mathrm{~T}$. serialis specimens.

Adult tapeworms were stained with acetocarmine, dehydrated in ethanol, cleared in methyl salicylate, and mounted in Canada balsam. Measurements were made using a compound microscope and ocular micrometer. For adult Mesocestoides spp., the following characters were measured: width of the scolex at the widest point, diameter of the suckers, and diameter of the paruterine organ in mature proglottids. For adult Taenia spp., measurements included scolex width, sucker diameter, and total length of the small and large rostellar hooks. Multivariate statistics (MANOVA) were used for comparison of these measurements among Mesocestoides spp. clades A, B, and C (Wilk's Lambda) and between Taenia species ( $\mathrm{F}$ test). In addition, a 1-way ANOVA was performed on each character. Analyses were performed with the JMP IN statistical program (SAS Institute, 2000).

\section{PCR amplification and sequence analysis}

DNA was extracted from whole metacestodes or proglottids with the Qiagen DNeasy Tissue Kit (Qiagen, Hilden, Germany) using the manufacturer's protocol. Polymerase chain reaction (PCR) amplifications were performed on 2 gene fragments. A 314-bp fragment of mitochondrial $12 \mathrm{~S}$ rDNA was amplified using cestode-specific primers 60.for. (5'-TTAAGATATATGTGGTACAGGATTAGATACCC-3') and 375. REV. (5'-AACCGAGGGTGACGGGCGGTGTGTACC-3') (NickischRosenegk et al., 1990). As previously reported (Gasser and Chilton, 1995; Crosbie et al., 1998), amplification of a 600-700-bp region of ITS-2 nuclear rDNA was accomplished using primers NC-6 (5'-ATC GACATCTTGAACGCACATTGC-3') and NC-2 (5'-TTAGTTTCTTT TCCTCCGCT-3'). Total volume for PCR reactions was $100 \mu \mathrm{l}$, comprising $20 \mu \mathrm{l}$ of DNA extract, $54.6 \mu \mathrm{l}$ of sterile water, $5 \mu \mathrm{l}$ of each primer, $2 \mu l$ of $10 \mathrm{mM}$ dNTP mix, $10 \mu l$ 10x PCR buffer, $3.0 \mu 1 \mathrm{MgCl}_{2}$ (1.5 mM final concentration), and $0.4 \mu \mathrm{l}$ (5 units/ $\mu \mathrm{l}$ ) Taq Polymerase (Invitrogen, Carlsbad, California). Automated nucleotide sequencing was performed by Davis Sequencing (Davis, California) and University of California Davis, Division of Biological Sciences sequencing facilities. Both strands were sequenced for all PCR products. Complementary sequences were assembled and edited using Sequencher version 3.0 (Gene Codes, Ann Arbor, Michigan). Regions that corresponded to the PCR primers were removed from the sequences before sequence alignment and phylogenetic analysis.

\section{Phylogenetic Analyses}

Sequences of Mesocestoides spp. clades A, B, and C and T. crassiceps, T. pisiformis, and T. serialis were aligned for both $12 \mathrm{~S}$ and ITS2 gene regions using Se-Al version 2.0 (Rambaut, 1996) and checked for variable nucleotides. Trees were constructed by maximum parsimony using PAUP*4.0 (heuristic search with 1,000 replicates of random stepwise addition). Support for clades was assessed by bootstrap resampling (1,000 replicates) and maximum-parsimony inference. All trees were rooted using Taenia crassiceps as the out-group. This out-group choice was based on morphological evidence that Taeniidae and Mesocestoididae are closely related families (Hoberg et al., 1999) and that T. crassiceps is sister to T. pisiformis and T. serialis (Hoberg et al., 2000). Certain published $12 \mathrm{~S}$ rDNA sequences from GenBank were also included in phylogenetic analyses: M. vogae (L49448), Mesocestoides lineatus (L49450), and Mesocestoides leptothylacus (L49451) (Nickisch-Rosenegk et al., 1999).

\section{RESULTS}

\section{Morphometrics}

Analyses of morphological data revealed significant differences among all Mesocestoides clades and between Taenia species for all characters $(P<0.0001)$ (Tables III, IV). The results were identical for each character analyzed separately by ANOVA.

Morphometric analyses suggest that variation in the morphological characters analyzed is similar in Mesocestoides and Taenia spp. Coefficients of variation (CV) for morphological character measurements showed moderate variation within Mesocestoides clades (CV for clades A, B, and C for scolex: $14.8 \%$, 19.5\%, 17.3\%; sucker: $10.2 \%, 13.6 \%, 15.7 \%$; paruterine organ: $14.4 \%, 13.0 \%, 18.1 \%$ ). Not surprisingly, the CV for pooled Mesocestoides spp. clades was greater than for individual clades (scolex: $22.1 \%$, sucker: $24.5 \%$, paruterine organ: $21.3 \%$ ). For $T$. pisiformis and $T$. serialis, the scolex was more variable than were other characters, such as the rostellar hooks (CV for $T$. pisiformis and T. serialis scolex: $24.0 \%, 26.5 \%$; sucker: $15.6 \%$, 14.5\%; external rostellar hook: $5.3 \%, 15.5 \%$; internal rostellar hook: $12.4 \%, 11.4 \%)$. As in Mesocestoides, the $\mathrm{CV}$ for pooled Taenia spp. measurements was greater (scolex: $35.2 \%$, sucker: $22.5 \%$, external rostellar hook: $23.6 \%$, internal rostellar hook: $27.0 \%)$.

Morphometric variation within clades of Mesocestoides spp. was no more variable than within Taenia spp. However, it was difficult to make systematic assessments based on morphomet- 
TABLE I. DNA sequence data from Mesocestoides and Taenia spp.

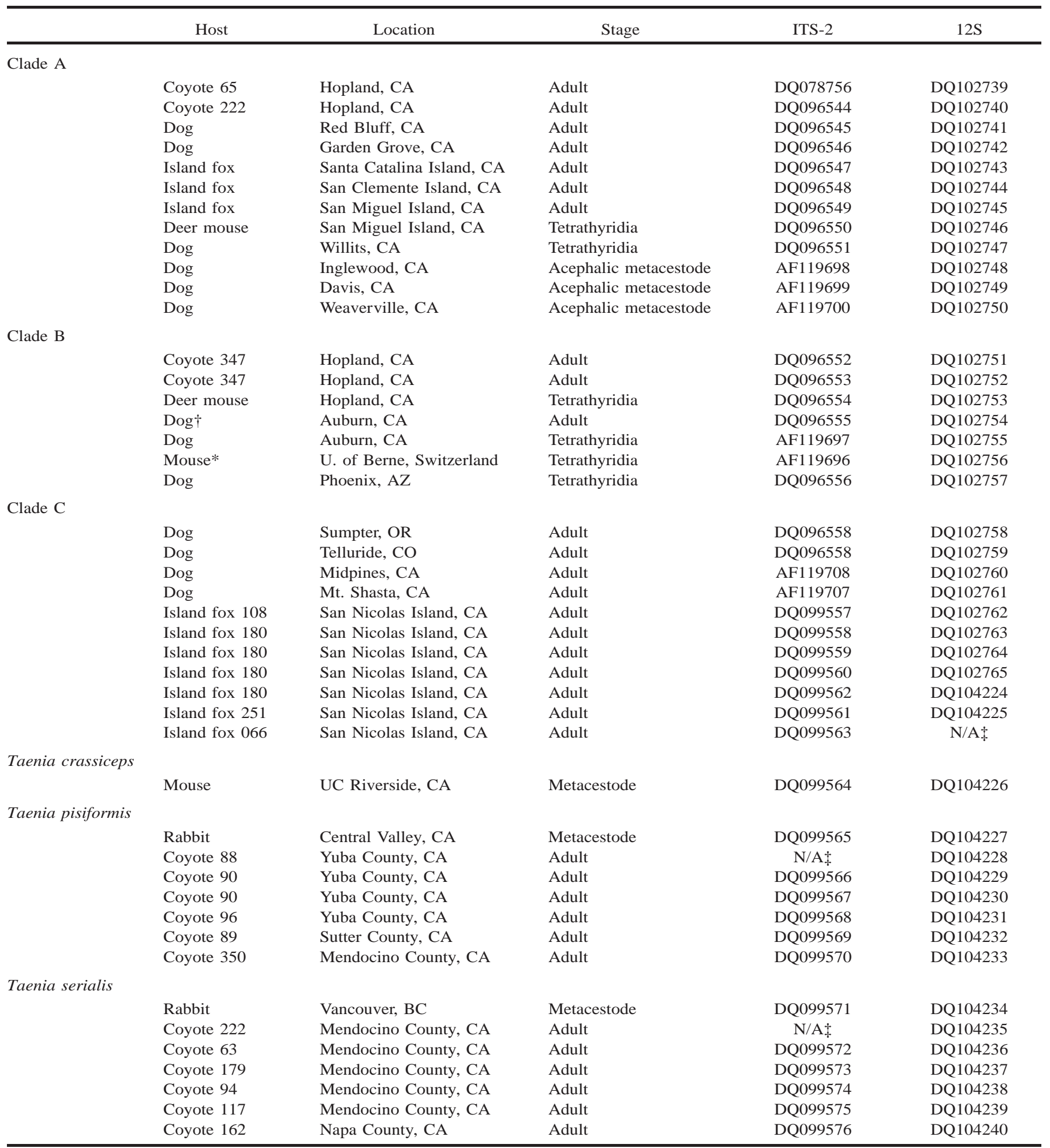

* Laboratory strain of Mesocestoides vogae; original host a western fence lizard from California (Specht and Voge, 1965)

† Dog experimentally infected using Mesocestoides tetrathyridia from dog (Padgett and Boyce, 2004).

$\$$ Sequence not included due to repeated failure of PCR amplification. 
TABLE II. Host and collection locality of adult tapeworms used in morphometric analyses.

\begin{tabular}{lrlll}
\hline Clade/Species & Number & \multicolumn{1}{c}{ Host } & \multicolumn{1}{c}{ Locality } & Collector \\
\hline Mesocestoides & & & & \multicolumn{1}{c}{ Accession no. } \\
A & 10 & Island fox & Santa Catalina Island, CINP & Dr. Linda Munson \\
A & 9 & Island fox & San Clemente Island, CINP & Dr. Linda Munson \\
A & 12 & Coyote & Mendocino Co., CA & K.A. Padgett \\
B & 25 & Domestic dog* & Placer Co., CA & K.A. Padgett \\
C & 18 & Island fox & San Nicolas Island, CINP & Dr. Linda Munson \\
Taenia & & & & N/A \\
pisiformis & 14 & Coyote & Sutter Co., CA & N/A \\
pisiformis & 9 & Coyote & Yuba Co., CA & K.A. Padgett \\
pisiformis & 1 & Coyote & Webb Co., TX & K.A. Padgett \\
pisiformis & 1 & Gray fox & Escamia Co., FL & L. Windberg \\
pisiformis & 2 & Bobcat & Brown Co., NE & J.A. Conti \\
pisiformis & 1 & Bobcat & Brown Co., NE & K.L. Tiekotter \\
pisiformis & 2 & Bobcat & Pawnee Co., NE & K.L. Tiekotter \\
pisiformis & 1 & Coyote & Muhlenberg Co., KY & K.L. Tiekotter \\
pisiformis & 2 & Domestic dog & NWT, Fort Smith, Canada & R.P. Myers \\
serialis & 7 & Coyote & Napa Co., CA & W.E. McIntyre \\
serialis & 3 & Coyote & Mendocino Co., CA & K.A. Padgett \\
serialis & 6 & Domestic dog & Athenia Co., NJ & K.A. Padgett \\
serialis & 10 & Domestic dog* & Alaska & A.C. Carlton \\
serialis & 5 & Mountain lion & Union Co., OR & Dr. Robert Rausch \\
\hline
\end{tabular}

* Experimental infection.

rics because of the extent of variation among Mesocestoides spp. clades and the overlap in range of values for characters measured. In comparative analysis with museum type and voucher specimens, clade B adult tapeworms were found to be most similar to $M$. variabilis and $M$. bassarisci in measurements of 3 morphological characters (scolex width, sucker diameter, and paruterine organ). Measurements for M. variabilis $(\mathrm{n}=4)$ : scolex width $($ mean $=353.3$, range: $328.4-408.0, \mathrm{SD}=37.7)$,

TABLE III. Measurements of adult Mesocestoides spp. from North American dogs and wildlife.

\begin{tabular}{|c|c|c|c|}
\hline $\begin{array}{l}\text { Molecular } \\
\text { strain }\end{array}$ & $\begin{array}{c}\text { Scolex } \\
\text { width }(u \mathrm{~m})\end{array}$ & $\begin{array}{c}\text { Sucker } \\
\text { diameter }(u \mathrm{~m})\end{array}$ & $\begin{array}{c}\text { Paruterine organ } \\
\text { diameter }(u \mathrm{~m})\end{array}$ \\
\hline \multicolumn{4}{|l|}{ Clade A } \\
\hline $\begin{array}{l}\text { Mean } \\
\text { Range }\end{array}$ & $\begin{array}{c}405.5 \\
(245.0-497.5)\end{array}$ & $\begin{array}{c}178.1 \\
(149.0-200.0)\end{array}$ & $\begin{array}{c}327.4 \\
(230.0-398.0)\end{array}$ \\
\hline $\begin{array}{l}\text { Standard } \\
\text { deviation } \\
\text { Number }\end{array}$ & $\begin{array}{c}59.8 \\
25\end{array}$ & $\begin{array}{c}18.2 \\
26\end{array}$ & $\begin{array}{c}47.1 \\
18\end{array}$ \\
\hline \multicolumn{4}{|l|}{ Clade B } \\
\hline $\begin{array}{l}\text { Mean } \\
\text { Range }\end{array}$ & $\begin{array}{c}325.0 \\
(219.0-407.0)\end{array}$ & $\begin{array}{c}130.7 \\
(100.0-180.0)\end{array}$ & $\begin{array}{c}299.9 \\
(200.0-365.0)\end{array}$ \\
\hline $\begin{array}{l}\text { Standard } \\
\text { deviation }\end{array}$ & 63.4 & 17.8 & 39.1 \\
\hline Number & 24 & 25 & 25 \\
\hline \multicolumn{4}{|l|}{ Clade C } \\
\hline $\begin{array}{l}\text { Mean } \\
\text { Range } \\
\text { Standard }\end{array}$ & $\begin{array}{c}466.3 \\
(325.0-587.0)\end{array}$ & $\begin{array}{c}222.1 \\
(150.0-278.0)\end{array}$ & $\begin{array}{c}446.4 \\
(298.0-547.3)\end{array}$ \\
\hline deviation & $\begin{array}{c}80.7 \\
16\end{array}$ & $\begin{array}{c}34.8 \\
14\end{array}$ & $\begin{array}{c}80.9 \\
8\end{array}$ \\
\hline
\end{tabular}

sucker diameter $($ mean $=145.0$; range: $140-150, \mathrm{SD}=5.8)$, paruterine organ $($ mean $=326.0$; range: $298.5-348.3, \mathrm{SD}=$ 20.6). Voucher specimens of $M$. bassarisci $(\mathrm{n}=22)$ measured as follows: scolex width (mean $=331.3$, range: $275.0-380$, SD $=31.7)$, sucker diameter $($ mean $=118.2$, range: $100-140, \mathrm{SD}$ $=11.0$ ), paruterine organ $($ mean $=143$, range: $90-175, \mathrm{SD}=$ 33.7). Mesocestoides bassarisci were small and appeared immature; only 6 of 22 had paruterine organs, and these did not appear fully developed. There was no statistical difference between $M$. bassarisci and clade B in the size of the scolex $(P=$ $0.68)$ and the sucker $(P=0.0063)$. Scolex, sucker, and paruterine organ measurements of $M$. kirbyi and $M$. manteri were both outside the range of clade B and fit most closely within the range of measurements for clade A (M. kirbyi type specimen [497.5; 189.1; 447.8] and M. manteri type specimen [497.5; $179.1 ; 358.2])$. Measurements of morphological characters of clade $\mathrm{C}$ did not match any type specimen included in these analyses.

\section{$12 S$ mitochondrial sequence data and analysis}

The amplified region of Mesocestoides spp. and Taenia spp. $12 \mathrm{~S}$ sequences were variable in length (primer sequences removed): clade A (347 nt), clade B (352 nt), clade C (349 nt), $T$. pisiformis (320 nt), T. serialis $(324 \mathrm{nt})$, and $T$. crassiceps (321 nt). The average base composition of Mesocestoides spp. was 0.29 (A), $0.13(\mathrm{C}), 0.19(\mathrm{G})$, and $0.39(\mathrm{~T})$. The average base composition of Taenia spp. was 0.26 (A), 0.16 (C), 0.18 $(\mathrm{G})$, and $0.40(\mathrm{~T})$. There were no significant differences in base composition among Mesocestoides spp. clades or Taenia spp. species. There was a slightly higher frequency of the nucleotide $\mathrm{T}$ in Taenia than in Mesocestoides $(P=0.0004)$.

Analysis of Mesocestoides spp. 12S data yielded a bootstrap consensus tree that represented M. lineatus and M. leptothyla- 
TABLE IV. Measurements of adult Taenia pisiformis and T. serialis from North American dogs and wildlife.

\begin{tabular}{|c|c|c|c|c|}
\hline Species & $\begin{array}{c}\text { Scolex } \\
\text { width }(u \mathrm{~m})\end{array}$ & $\begin{array}{c}\text { Sucker } \\
\text { diameter }(u \mathrm{~m})\end{array}$ & \multicolumn{2}{|c|}{ Total length of rostellar hooks } \\
\hline Mean & 940.2 & 300.8 & 140 & 235.1 \\
\hline Range & $(537.3-1552.0)$ & $(200.0-378.1)$ & $(129.0-149.3)$ & $(139.0-268.7)$ \\
\hline Standard deviation & 225.6 & 46.9 & 7.44 & 29.1 \\
\hline Number & 30 & 30 & 29 & 20 \\
\hline Mean & 547.7 & 268 & 86.4 & 145.3 \\
\hline Range & $(250.0-815.9)$ & $(115.0-268.0)$ & $(60.0-110.0)$ & $(90.0-175.0)$ \\
\hline Standard deviation & 145.1 & 30.9 & 13.34 & 16.5 \\
\hline Number & 20 & 20 & 18 & 21 \\
\hline
\end{tabular}

cus as sister to North American Mesocestoides spp. (Fig. 1A). Within North American Mesocestoides spp. there was strong bootstrap support for clades A and B as sister taxa (100\%), with clade C sister to A plus B (100\%). Analysis of aligned $12 \mathrm{~S}$ sequences revealed sequence variation, partitioned as apomorphies for each Mesocestoides spp. clade (clade A, $\mathrm{n}=4$; clade $B, n=2$; clade $C, n=4$ ) (Table V; Fig. 2). These cladespecific sequence states involved 5 transition and 5 transversion substitutions.

For Taenia species, the tree based on $12 \mathrm{~S}$ data placed $T$. pisiformis and $T$. serialis as sister species with $T$. crassiceps sister to these species (Fig. 3); these relationships received strong bootstrap support. Analysis of Taenia spp. sequences revealed derived nucleotide character states for each species $(T$. pisiformis, $\mathrm{n}=10 ; T$. serialis, $\mathrm{n}=7$ ) (Table VI; Fig. 4). Differences between $T$. pisiformis and $T$. serialis for the $12 \mathrm{~S}$ sequence data involved 6 transition and 8 transversion substitutions, and 3 indels.

\section{ITS-2 sequence data and analysis}

The sequenced region of Mesocestoides spp. and Taenia spp. ITS-2 was length-variable: clade A (472 nt), clade B (494 nt), clade C (482 nt), T. pisiformis (538 nt), T. serialis (516 nt), and $T$. crassiceps $(611 \mathrm{nt})$. Although there were no significant differences in the average base composition among Mesocestoides spp. clades $(\mathrm{A}=0.19, \mathrm{C}=0.23, \mathrm{G}=0.34$, and $\mathrm{T}=0.27)$ or Taenia species $(\mathrm{A}=0.27, \mathrm{C}=0.34, \mathrm{G}=0.24$, and $\mathrm{T}=0.15)$,
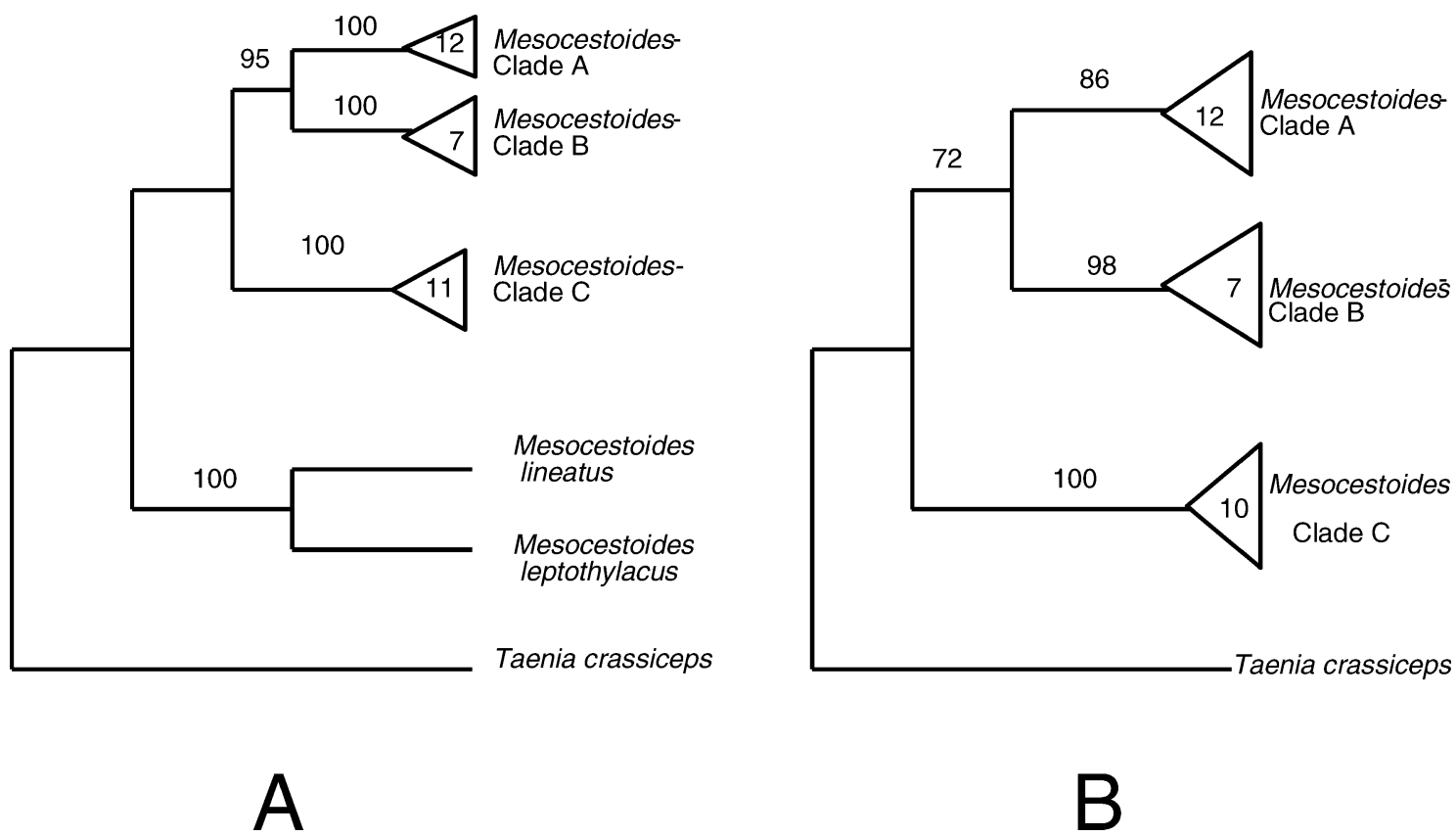

FIGURE 1. A. Phylogenetic relationships of Mesocestoides clades A, B, C, M. lineatus, M. leptothylacus, and Taenia crassiceps based on maximum parsimony using partial sequences of $12 \mathrm{~S}$ gene (strict consensus of 40 trees, tree length $=172, \mathrm{CI}=0.82, \mathrm{RI}=0.90, \mathrm{HI}=0.18 ; 109$ parsimony-informative/34 variable parsimony-uninformative sites). B. Maximum parsimony (strict consensus of 24 trees, tree length $=638$, CI $=0.90, \mathrm{RI}=0.89, \mathrm{HI}=0.10 ; 269$ parsimony-informative $/ 254$ variable parsimony uninformative sites) based on partial sequences of the ITS-2 gene for Mesocestoides spp. clades A, B, C, and T. crassiceps. All trees were rooted with T. crassiceps as out-group; numbers above branches represent bootstrap support (1,000 replicates). Number within clade triangle indicates the number of individuals sampled. 
TABLE V. Diagnostic sequence data from Mesocestoides tapeworms, Clades A, B, and C in relation to Taenia crassiceps (outgroup); apomorphies of $T$. crassiceps are not shown.

\begin{tabular}{|c|c|c|c|c|c|c|c|c|c|c|}
\hline & \multicolumn{10}{|c|}{ Position of variable characters for $12 \mathrm{~S}$} \\
\hline & 55 & 79 & 88 & 99 & 106 & 166 & 202 & 251 & 259 & 260 \\
\hline Taenia crassiceps & $\mathrm{G}$ & $\mathrm{T}$ & $\mathrm{T}$ & $\mathrm{T}$ & A & $\mathrm{T}$ & $\mathrm{T}$ & $\mathrm{T}$ & $\mathrm{T}$ & $\mathrm{T}$ \\
\hline Clade A & $\mathbf{A}$ & $\mathrm{T}$ & $\mathrm{T}$ & $\mathbf{C}$ & $\mathbf{G}$ & $\mathbf{A}$ & $\mathrm{T}$ & $\mathrm{T}$ & $\mathrm{T}$ & $\mathrm{T}$ \\
\hline Clade B & $\overline{\mathrm{G}}$ & $\mathrm{T}$ & $\mathrm{T}$ & $\overline{\mathrm{T}}$ & $\overline{\mathrm{A}}$ & $\overline{\mathrm{T}}$ & $\mathrm{T}$ & $\mathrm{T}$ & $\mathbf{A}$ & $\mathbf{A}$ \\
\hline \multirow[t]{3}{*}{ Clade C } & $\mathrm{G}$ & $\mathbf{A}$ & $\mathbf{C}$ & $\mathrm{T}$ & A & $\mathrm{T}$ & $\mathbf{A}$ & $\mathbf{G}$ & $\overline{\mathrm{T}}$ & $\overline{\mathrm{T}}$ \\
\hline & \multicolumn{9}{|c|}{ Position of variable characters for ITS-2 } & \\
\hline & 37 & 41 & 42 & 52 & 60 & 74 & 108 & 143 & 668 & \\
\hline Taenia crassiceps & $\mathrm{G}$ & $\mathrm{T}$ & A & $\mathrm{T}$ & $\mathrm{T}$ & $\mathrm{G}$ & G & G & $\mathrm{C}$ & \\
\hline Clade A & $\mathrm{G}$ & $\mathbf{A}$ & A & $\mathrm{T}$ & $\mathrm{T}$ & $\mathbf{A}$ & G & G & $\mathrm{C}$ & \\
\hline Clade B & $\mathrm{G}$ & $\overline{\mathrm{T}}$ & A & $\mathrm{T}$ & $\mathrm{T}$ & $\overline{\mathrm{G}}$ & $\mathbf{A}$ & $\mathbf{A}$ & $\mathrm{C}$ & \\
\hline Clade C & $\mathbf{C}$ & $\mathrm{T}$ & C & C & G & $\mathrm{G}$ & $\overline{\mathrm{G}}$ & $\overline{\mathrm{G}}$ & $\mathbf{A}$ & \\
\hline
\end{tabular}

the difference in base frequency between Mesocestoides and Taenia was significant for all nucleotides $(P<0.0001)$. Strict consensus trees constructed using ITS-2 sequence data had trees with the same topology as trees constructed from $12 \mathrm{~S}$ sequence data (Fig. 1B). All individuals of clade A, B, and C Mesocestoides clustered into monophyletic groups as did T. pisiformis and T. serialis with bootstrap support from 86-100\%.

Autapomorphies also were recovered within ITS- 2 sequences for Mesocestoides spp. clades and Taenia species. Mesocestoides spp. ITS-2 sequences had derived nucleotide differences (2 transitions and 7 transversions): clade A $(n=2)$, clade B $(n=$ 2), and clade C ( $\mathrm{n}=5)$ (Table V; Fig. 2). Similarly, Taenia species had fixed nucleotide character autapomorphies (2 transitions and 8 transversions) for $T$. pisiformis $(\mathrm{n}=5)$ and $T$. serialis $(n=5)$ (Table VI; Figure 4). Hence, the distribution of these autapomorphies, representing separate nuclear and mitochondrial loci, are inconsistent with the null hypothesis that these Mesocestoides isolates represent a single species.

\section{DISCUSSION}

This study is the first to address the taxonomic status of $\mathrm{Me}$ socestoides spp. cestodes using data from multiple genetic loci

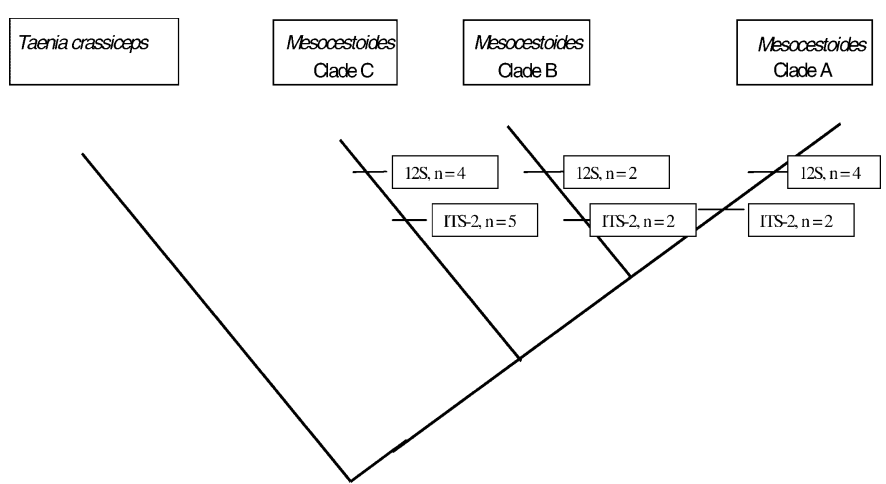

FIgURE 2. Autapomorphies of Mesocestoides clades A, B, and C based on out-group comparison (Taenia crassiceps) of $12 \mathrm{~S}$ mitochondrial and ITS-2 nuclear DNA data sets. For each DNA region (12S or ITS-2), the number within each box represents the corresponding number of character state changes; see Table $\mathrm{V}$ for specific changes. and a hypothesis-testing framework. Systematics is a vibrant component of parasitological research, with new species described frequently, e.g., an average of 5 new species per issue in the Journal of Parasitology during 2003. Although most parasite species are successfully delimited by the similarity species concept, some species are clearly less amenable to this approach. Here, an objective hypothesis-testing approach was applied and the results strongly support species status for each of 3 clades that were previously recognized (Crosbie, Nadler et al., 2000.). This methodology is applicable to many organisms and has been applied to systematic questions involving entomopathogenic and parasitic nematodes (Adams, 1998; Nadler et al., 2000; Nadler, 2002).

Although several Mesocestoides species have been described based on qualitative morphologic features (e.g., Voge, 1955; Loos-Frank, 1990), some qualitative characters are potentially

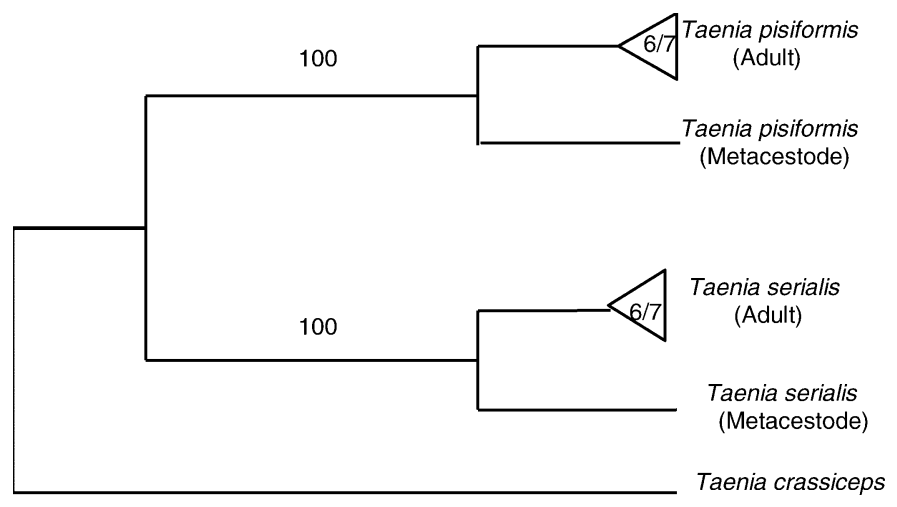

FIGURE 3. Phylogenetic relationships of Taenia crassiceps, T. pisiformis, and $T$. serialis (metacestodes of $T$. pisiformis and $T$. serialis from rabbit hosts included). Tree based on maximum parsimony using partial sequences of $12 \mathrm{~S}$ gene (strict consensus of 264 trees, tree length $=101, \mathrm{CI}=0.88, \mathrm{RI}=0.94, \mathrm{HI}=0.12 ;(42$ parsimony-informative/ 32 parsimony-uninformative sites) and on partial sequences of ITS-2 gene $(1$ tree, tree length $=765, \mathrm{CI}=0.85, \mathrm{RI}=0.85, \mathrm{HI}=0.15 ; 216$ parsimony-informative/242 variable parsimony uninformative sites). Number within species triangle indicates the number of individuals sampled $(6=$ ITS $-2 ; 7=12 \mathrm{~S})$. Trees were rooted with Taenia crassiceps as out-group; numbers above branches represent bootstrap support (1,000 replicates). Both data sets yielded identical consensus trees (consensus tree shown here). 
TABLE VI. Diagnostic DNA sequence data from Taenia. Apomorphies from Taenia crassiceps (outgroup) are unlisted except those shared with T. pisiformis and T. serialis.

\begin{tabular}{|c|c|c|c|c|c|c|c|c|c|c|c|c|c|c|c|c|c|}
\hline & \multicolumn{17}{|c|}{ Position of variable characters for $12 \mathrm{~S}$} \\
\hline Taenia crassiceps & $\mathrm{T}$ & A & G & $\mathrm{T}$ & G & $\mathrm{T}$ & $\mathrm{T}$ & A & $\mathrm{T}$ & $\mathrm{T}$ & G & GAP & $\mathrm{T}$ & $\mathrm{T}$ & $\mathrm{T}$ & G & A \\
\hline \multirow[t]{2}{*}{ Taenia serialis } & $\overline{\mathrm{T}}$ & $\underline{\mathbf{G}}$ & $\overline{\mathrm{G}}$ & $\underline{\mathbf{G}}$ & $\overline{\mathrm{G}}$ & $\mathrm{T}$ & $\mathrm{T}$ & $\underline{\mathbf{G}}$ & $\overline{\mathrm{T}}$ & $\overline{\mathrm{T}}$ & $\overline{\mathrm{G}}$ & $\underline{\mathbf{C}}$ & $\overline{\mathrm{T}}$ & $\underline{\mathbf{A}}$ & $\underline{\mathbf{A}}$ & $\overline{\mathrm{G}}$ & $\underline{\mathbf{T}}$ \\
\hline & \multicolumn{10}{|c|}{ Position of variable characters for ITS-2 } & & & & & & & \\
\hline Taenia crassiceps & G & $\mathrm{T}$ & $\mathrm{C}$ & A & $\mathrm{C}$ & $\mathrm{T}$ & $\mathrm{T}$ & $\mathrm{T}$ & A & $\mathrm{C}$ & & & & & & & \\
\hline Taenia pisiformis & $\mathbf{A}$ & $\mathrm{T}$ & $\mathrm{C}$ & A & $\mathbf{G}$ & $\mathrm{T}$ & $\mathbf{C}$ & $\mathrm{T}$ & $\mathbf{G}$ & $\mathbf{T}$ & & & & & & & \\
\hline Taenia serialis & $\overline{\mathrm{G}}$ & $\mathbf{A}$ & $\mathbf{A}$ & $\mathbf{G}$ & $\overline{\mathrm{C}}$ & $\mathbf{C}$ & $\overline{\mathrm{T}}$ & $\mathbf{C}$ & $\overline{\mathrm{A}}$ & $\overline{\mathrm{C}}$ & & & & & & & \\
\hline
\end{tabular}

subjective. Thus, there is a clear need to clarify the taxonomy of Mesocestoides species by using characters independent of morphology, e.g., molecular sequences, and to assess the extent of morphological variation within this genus. Using morphometric analysis, significant differences were found among Taenia species and the Mesocestoides spp. clades. The morphometric values for Taenia spp. fall within the range given by Verster (in Loos-Frank, 2000), as well as other studies (Esch and Self, 1965; Gubanyi, 1995). Mesocestoides spp. clades A and $\mathrm{B}$ were more similar morphologically to each other than either was to clade $\mathrm{C}$, consistent with molecular phylogenies that depict clades A and B as sister groups (Crosbie, Nadler et al., 2000; this study). Although it has been suggested that $\mathrm{Me}$ socestoides spp. has a comparatively high degree of morphological variability (Voge, 1955; Specht and Voge, 1965; Rausch 1994; Gubanyi and Eszterbauer, 1998), the amount of phenotypic diversity measured within clades of adult Mesocestoides spp. was similar to that found within species of Taenia. Thus, a high level of intraspecific morphological plasticity per se would not appear to be responsible for the difficulties in $\mathrm{Me}$ socestoides species-level systematics. One potential caveat to this interpretation is that a limited range of definitive hosts was used as the source of cestode adults in morphometric analyses, and the influence of a wide range of final host species on $\mathrm{Me}$ socestoides spp. morphology remains unexplored.

In addition to being morphologically distinct, cladistic anal-

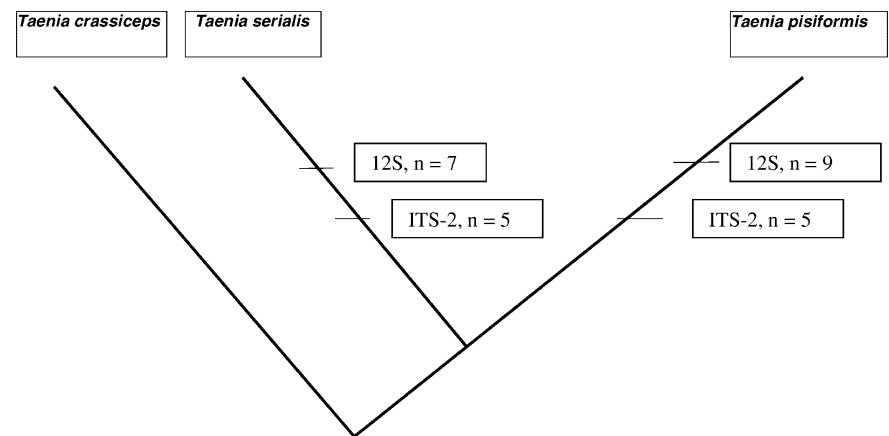

FIgURE 4. Autapomorphies of Taenia pisiformis and T. serialis based on out-group comparison (T. crassiceps) of $12 \mathrm{~S}$ mitochondrial and ITS-2 nuclear DNA data sets. For each DNA region (12S or ITS2 ), the number within each box represents the corresponding number of character state changes; see Table VI for specific changes. yses support that these 3 genetically defined clades of Mesocestoides spp. are separate evolutionary lineages, consistent with their recognition as separate species. The same evolutionary approach and genetic loci delimited $T$. pisiformis and $T$. serialis as distinct species. Phylogenetic analyses based on both the nuclear ITS-2 and mitochondrial 12S gene fragments agreed with previously published trees for Taenia spp. based on morphological characters (Hoberg et al., 2000) and for Mesocestoides spp. based on molecular characters (Crosbie, Nadler et al., 2000.). In testing whether there is evidence that Mesocestoides spp. clades $\mathrm{A}, \mathrm{B}$, and $\mathrm{C}$ are independent lineages, the following null hypothesis was tested: "there are no derived molecular characters unique to each lineage, i.e., autapomorphies." Although each lineage must have at least 1 apomorphy to demonstrate evolutionary independence, multiple apomorphies were recovered for each gene and for each clade (Mesocestoides spp.) or species (Taenia spp.). Thus, the null hypothesis was rejected, resulting in the conclusion that the 3 clades showed evidence of lineage exclusivity and thus represent distinct species.

To decrease the probability of mistaking the evolutionary history of a single genetic region for that of the taxa involved, both nuclear and mitochondrial sequence data were used in these comparisons. The highly variable ITS-2 region of the nuclear rDNA has been useful for many systematic studies of helminths (Gasser and Chilton, 1995; Crosbie, Nadler et al., 2000; Nadler et al., 2000; Luo et al., 2002). In Mesocestoides spp., Crosbie, Nadler et al. (2000) found the ITS-2 region yielded more informative variation than a similar-sized region of $18 \mathrm{~S}$ rDNA, which placed clades A and B together in a monophyletic group. Likewise, because of its fast evolutionary rate and lack of recombination, mitochondrial DNA is often used in molecular population genetics and phylogenetic studies that involve closely related taxa. The $12 \mathrm{~S}$ mitochondrial gene fragment used in this study is composed of highly variable noncoding regions, flanked by conserved stretches (Nickisch-Rosenegk et al., 1999). This mitochondrial region provided more apomorphies than did the ITS-2 region, most notably for Taenia species.

The hypothesis-based approach to species delimitation requires care in planning and in interpretation of results. Instead of simply measuring the degree of differences, e.g., sequence differences among putative species, hypotheses of species should be tested using an evolutionary, e.g., phylogenetic, 
framework, evaluating evidence of lineage independence rather than merely genetic distances. To avoid confounding individual or population level differences with species, multiple samples of each taxon should be included, ideally, samples from a broad geographic range and in the case of generalist parasites, from a broad range of definitive hosts. Finally, evidence of evolutionary history should be acquired from independent genetic loci to avoid mistaking gene trees for species trees. In this study, we addressed these requirements by including 7-12 samples of each taxon in question. Samples were collected from a broad geographic region of western North America, including the California Channel Islands and from different host species. Finally, sequence data from 2 independent loci, i.e., mitochondrial and nuclear genetic regions, were included in these analyses.

Molecular phylogenetic results from this study indicate that tapeworms in clade B represent the species $M$. vogae (previously Mesocestoides corti, Etges, 1991). This designation is supported also by morphological data that show clade B individuals fall within the range of morphological values for $M$. vogae (Voge, 1955). Furthermore, morphological evidence presented here, i.e., measurements of scolex width, sucker diameter, and paruterine organ, supports synonym status for $M$. vogae and M. variabilis first proposed by Voge (1955). Based on the available morphological data, it is not possible to determine whether clades A and C are previously described Mesocestoides species. Clade A specimens closely resemble both $M$. kirbyi (originally isolated from a coyote in California) and M. manteri (isolated from a lynx in Nebraska). Voge (1955) noted that $M$. manteri matched Mesocestoides from island fox from Santa Rosa Island, Channel Islands N.P. in several key morphological characters (size range of organs and testis number); we were unable to obtain Mesocestoides spp. from Santa Rosa island fox to include in these analyses. Clade $\mathrm{C}$ individuals are much larger tapeworms than any of the Mesocestoides spp. voucher specimens measured in this study and likely represent an undescribed species.

We present evidence that Mesocestoides clades A, B, and C are distinct species and that clade $\mathrm{B}$ is conspecific with $M$. vogae. This study illustrates the practical application of sequence data to test the hypothesis of lineage independence and species status for cestodes. Assuming that species can be represented as separate evolutionary lineages, phylogenetic methods can be applied to delimit species in nature (Adams, 2001). Other systematically intractable cestode taxa may benefit from this method of species delimitation (i.e. strains/subspecies of Echinococcus granulosus (Le et al., 2002)), by using comparative analyses of large datasets of sister taxa. This approach should be applied in concert with comparative morphological analyses to assign species names and to develop standard morphological descriptions, when feasible. The life cycles of $\mathrm{Me}$ socestoides spp. remain enigmatic, but future life history studies should recognize clades A, B, and C as separate Mesocestoides species, with potentially distinct life histories.

\section{ACKNOWLEDGMENTS}

We thank Grace Lee (UC Davis) for enlightening discussions and excellent technical assistance. We are sincerely grateful to all those who provided material: Robert Rausch (University of Washington), Karen Terio (UC Davis), Edward G. Platzer (UC Riverside), Tim Coonan
(Channel Islands National Park), Grace Smith (U.S. Navy), Dave Garcelon (Institute for Wildlife Studies), and Janne Potter (West Boulevard Veterinary Clinic, Vancouver, British Columbia, Canada). We would also like to thank Robin Houston for help with mounting tapeworms and Tanya Scharaschkin for helpful comments on phylogenetic analysis. This project was partially supported by a grant from the Center for Companion Animal Health, School of Veterinary Medicine, UC Davis (W. M. Boyce \& K. A. Padgett), a grant from the UC Davis Center for Biosystematics (K. A. Padgett), and a Jastro Shields Research Fellowship (K. A. Padgett).

\section{LITERATURE CITED}

ADAms, B. J. 1998. Species concepts and the evolutionary paradigm in modern nematology. Journal of Nematology 30: 1-21.

- 2001. The species delimitation uncertainty principle. Journal of Nematology 33: 153-160.

Bowles, J., AND D. P. McManus. 1994. Genetic characterization of the Asian Taenia, a newly described taeniid cestode of humans. American Journal of Tropical Medicine and Hygiene 50: 33-44.

Cracraft, J. 1983. Species concepts and speciation analysis. Current Ornithology 1: 159-187.

Crosbie, P. R., W. M. Boyce, E. G. Platzer, S. A. Nadler, and C. KERNER. 1998. Diagnostic procedures and treatment of eleven dogs with peritoneal infections caused by Mesocestoides spp. Journal of the American Veterinary Association 213: 1578-1583.

, S. A. Nadler, E. G. Platzer, C. Kerner, J. Mariaux, and W. M. BoyCE. 2000. Molecular systematics of Mesocestoides spp. (Cestoda: Mesocestoididae) from domestic dogs (Canis familaris) and coyotes (Canis latrans). Journal of Parasitology 86: 350-357.

, K. A. PAdGetT, AND W. M. Boyce. 2000. Mesocestoides spp. tapeworm infections in dogs in California. California Veterinarian May/June: $15-28$.

De Quieroz, A., AND N. L. Alkire. 1998. The phylogenetic placement of Taenia cestodes that parasitize humans. Journal of Parasitology 84: 379-383.

Esch, G., AND J. T. Self. 1965. A critical study of the taxonomy of Taenia pisiformis Bloch, 1780; Multiceps multiceps (Leske, 1780); and Hydatigera Taeniaeformis Batsch, 1786. Journal of Parasitology 51: 932-937.

EtGes, F. J. 1991. The proliferative tetrathyridium of Mesocestoides vogae sp. n. (Cestoda). Journal of the Helminthological Society of Washington 58: 181-185.

Gasser, R. B., ANd N. B. Chilton. 1995. Characterization of taeniid cestode species by PCR-RFLP of ITS2 ribosomal DNA. Acta Tropica 59: 31-40.

GubanYI, A. 1995. Morphometrics of taeniid tapeworms I. Multivariate analysis of distance measurements of the rostellar hooks. Parasitologica Hungarica 28: 21-41.

, AND E. EszTERbauer. 1998. Morphological investigation of Mesocestoides (Cestoda, Mesocestoididae) species parasitizing $\mathrm{Vul}$ pes vulpes in Hungary. Miscellanea Zoologica Hungarica 12: 1119.

Hoberg, E. P., A. Jones, And R. A. Bray. 1999. Phylogenetic analysis among the families of the Cyclophyllidea (Eucestoda) based on comparative morphology, with new hypotheses for co-evolution in vertebrates. Systematic Parasitology 42: 51-73.

- - R. L. Rausch, K. S. EOM, AND S. L. Gardner. 2000. A phylogenetic hypothesis for species of the genus Taenia (Eucestoda: Taeniidae). Journal of Parasitology 86: 89-98.

Le, T. H., M. S. Pearson, D. Blair, N. Dai, L. H. Zhang, and D. P. MCMANUS. 2002. Complete mitochondria genomes confirm the distinctiveness of the horse-dog and sheep-dog strains of Echinococcus granulosus. Parasitology 124: 97-112.

Loos-Frank, B. 1987. Shedding of gravid proglottids and in experimental infections of foxes with Mesocestoides leptothylacus LoosFrank, 1980 (Cestoda). Journal of Helminthology 61: 213-218.

- 1990. Cestodes of the genus Mesocestoides (Mesocestoididae) from carnivores in Israel. Israel Journal of Zoology 37: 3-13.

. 2000. An up-date of Verster's (1969) 'Taxonomic revision of the genus Taenia Linnaeus' (Cestoda) in table format. Systematic Parasitology 45: 155-183. 
Luo, H. Y., Y. A. Zhang, G. T. WANG, AND W. J. YaO. 2002. Molecular variation of Bothriocephalus acheilognathi Yamaguti, 1934 (Cestoda: Pseudophyllidea) in different fish host species based on ITS rDNA sequences. Systematic Parasitology 52: 159-166.

MAYR, E. 1963. Animal species and evolution. Belknap Press of Harvard University Press, Cambridge, Masachusetts, $797 \mathrm{p}$.

NADLER, S. A. 2002. Species delimitation and nematode biodiversity: phylogenies rule. Nematology 4: 615-625.

, B. J. Adams, E. T. Lyons, R. L. DeLong, and S. R. Melin. 2000. Molecular and morphometric evidence for separate species of Uncinaria (Nematoda: Ancylostomatidae) in California sea lions and northern fur seals: Hypothesis testing supplants verification. Journal of Parasitology 86: 1099-1106.

Nickisch-Rosenegk, M., R. Lucius, And B. Loos-Frank. 1999. Contributions to the phylogeny of the Cyclophyllidea (Cestoda) inferred from mitochondrial 12S rDNA. Journal of Molecular Evolution 48: 586-596.

Padgett, K. A., AND W. M. Boyce. 2004. Life history studies on two molecular strains of Mesocestoides (Cestoda: Mesocestoididae):
Identification of sylvatic hosts and infectivity of immature life stages. Journal of Parasitology 90: 108-114.

Rambaut, A. 1996. Se-Al: Sequence Alignment Editor. http://evolve. zoo.ox.ac.uk/.

Rausch, R. L. 1994. Family Mescestoididae Fuhrmann, 1907. In Keys to the cestode parasites of vertebrates, L. F. Khalil, A. Jones, and R. A. Bray (eds.). CAB International, Wallingford, U.K., p. 309314.

SAS InstituTe. 2000. JMP IN User's Manual, version 4.0, SAS Institute, Cary, North Carolina, $491 \mathrm{p}$.

SOKAL, R. R., AND F. J. RoHLF. 1997. Biometry: The principles and practices of statistics in biological research. 2nd ed. W. H. Freeman, San Francisco, California, $887 \mathrm{p}$

Specht, D., AND M. Voge. 1965. Asexual multiplication of Mesocestoides tetrathyridia in laboratory animals. Journal of Parasitology 51: 268-272.

Voge, M. 1955. North American cestodes of the genus Mesocestoides. University of California Publications in Zoology 59: 125-156.

WILEY, E. O. 1978. The evolutionary species concept reconsidered. Systematic Zoology 27: 17-26 